\title{
Defective Proboscis Extension Response (DPR), a Member of the Ig Superfamily Required for the Gustatory Response to Salt
}

\author{
Makoto Nakamura,, ${ }^{1,2}$ David Baldwin,, ${ }^{3}$ Susannah Hannaford, ${ }^{3}$ John Palka, ${ }^{3}$ and Craig Montell ${ }^{1}$ \\ ${ }^{1}$ Departments of Biological Chemistry and Neuroscience, The Johns Hopkins University School of Medicine, Baltimore, \\ Maryland 21205, 2Division of Morphogenesis, Department of Developmental Biology, National Institute of Basic Biology, \\ Okazaki 444-8585, Japan, and ${ }^{3}$ Department of Zoology, University of Washington, Seattle, Washington 98195
}

\begin{abstract}
Gustatory stimuli, such as sugar, induce a behavioral response in Drosophila that involves extension of the proboscis and consumption of the sugar-containing solution. Addition of salt to the sugar solution inhibits this behavioral response. However, the mechanisms and gene products involved in the salt aversion response have not been described. Here, we report the identification of a locus, defective proboscis extension response $(d p r)$, that is required for salt aversion. $d p r$ was ex-
\end{abstract}

pressed in a subset of primary neurons in the gustatory organs and encoded a protein with two Ig-like domains, a single putative transmembrane domain, and a short region $\mathrm{C}$ terminal to the transmembrane segment. In addition, DPR defines a large previously unknown group of $\geq 20$ highly related lg-containing proteins.

Key words: taste; Drosophila; immunoglobulin repeats; gustatory response; salt aversion; chemoreceptors
Gustatory organs are specialized sensory structures that function in the detection of soluble chemicals and are associated predominately with feeding (for review, see Kinnamon and Margolskee, 1996). In mammals, the gustatory organs (taste buds) are located on the epithelium of the tongue and soft palate. In Drosophila, gustatory organs, referred to as taste sensilla, are situated at many sites, including the labelum (a portion of the proboscis), pharynx, legs, wing margins, and female genitalia (Stocker, 1994; Singh, 1997; Shanbhag et al., 2001). Each taste sensillum contains a bristle that is innervated by one mechanosensory and four chemosensory neurons (Stocker, 1994).

Despite the differences in the morphology and distribution of the gustatory organs in mammals and Drosophila, there are some parallels between vertebrate and fly taste perception. Vertebrate taste receptors respond to a broad range of compounds, which comprise four or five classes of tastants (Lindemann, 1996). As is the case with vertebrates, Drosophila can also distinguish the four primary types of tastants: sweet, sour, salt, and bitter (Singh, 1997). Moreover, structurally similar families of putative sweet and bitter chemoreceptors are expressed in mammalian taste buds (Adler et al., 2000; Chandrashekar et al., 2000; Chaudhari et al., 2000; Matsunami et al., 2000; Max et al., 2001; Montmayeur et al., 2001; Nelson et al., 2001; Sainz et al., 2001) and Drosophila

Received Sept. 25, 2001; revised Jan. 29, 2002; accepted Feb. 12, 2002.

This work was supported by National Eye Institute Grant EY08117 (C.M.), National Science Foundation Grant IBN-9511241 (J.P.), and a Grant-in-Aid for Scientific Research (priority area C) from the Ministry of Education, Culture, Sports, Science, and Technology of Japan (M.N.). We thank Dr. A. Spradling for providing the P-element insertion lines used in the primary screen and Dr. K. Kimura for the poxn $n^{70-28}$ flies.

Correspondence should be addressed to Craig Montell, Department of Biological Chemistry and Department of Neuroscience, Room 408, Wood Basic Science Building, 725 N. Wolfe Street, The Johns Hopkins University School of Medicine, Baltimore, MD 21205. E-mail: cmontell@jhmi.edu.

D. Baldwin's present address: Northwest Fisheries Science Center, National Marine Fisheries Service, Seattle, WA 98112.

S. Hannaford's present address: Department of Biology, University of Puget Sound, Tacoma, WA 98416.

Copyright (C) 2002 Society for Neuroscience $\quad 0270-6474 / 02 / 223463-10 \$ 15.00 / 0$ taste organs (Clyne et al., 2000; Ishimoto et al., 2000; Dunipace et al., 2001; Scott et al., 2001; Ueno et al., 2001).

Other than the taste receptors, little is known concerning the molecules and molecular mechanisms underlying behavioral responses to gustatory stimuli. In particular, the molecular mechanisms by which an animal integrates its response to two or more types of tastants is not understood. Although animals are attracted by sweet compounds, the addition of high concentrations of salt to a sweet-containing solution evokes a negative reaction. In Drosophila, the salt response is mediated by two of the chemosensory neurons in the taste sensilla (Falk et al., 1976; Fujishiro et al., 1984; Arora et al., 1987). However, the mechanisms and gene products that are required for integrating the inhibitory salt response with the stimulatory sugar response have not been described.

In the current work, we describe the defective proboscis extension response $(d p r)$ locus, which is characterized by a reduced inhibitory response to salt. We identified the $d p r$ gene and found that it encoded a protein with a single predicted transmembrane segment and two Ig repeats. The DPR gene product was expressed in a subset of sensory neurons of the gustatory system and appears to define a new subfamily of proteins with Ig repeats.

\section{MATERIALS AND METHODS}

Genetics, fly stocks, and germline transformation. Fly culture and crosses were performed according to standard procedures. One of the P-element insertion lines generated in the Spradling laboratory [line PZ(2)6705] (Karpen and Spradling, 1992) was identified by screening for defects in fast phototaxis using the Benzer counter-current apparatus (Benzer, 1967). Subsequent to the primary screening, we found that PZ(2)6705 exhibited a defective salt aversion response. Genetic analyses revealed that PZ(2)6705 contained a second mutation independent of the P-element that failed to complement $h d c$, a locus shown previously to be required for the visual response (Burg et al., 1993). We segregated the P-element and $h d c$ by recombination and demonstrated that the P-element was solely responsible for the gustatory phenotype $\left(\mathrm{dpr}^{I R H}\right)$, and the $h d c$ mutation caused the defect in phototaxis.

The $d p r^{l e 5}$ and $d p r^{l e l 28}$ excision alleles were generated by crossing $d p r^{l}$ to a line referred to as jumpstarter or $\Delta 2-3$, which provided the P-element transposase required in trans for transposition. $d p r^{e s}$ was 
isolated among $72 r y^{-}$lines, all of which were homozygous viable, except for one that was semilethal. $c n ; r y^{506} ; \mathrm{dpr}^{+}$was used as the wild-type control. The deficiency stock, $\operatorname{Df}(2 \mathrm{R}) \mathrm{AA} 21$, was obtained from the Bloomington Stock Center. The breakpoints are 56F9-17 and 57D11-12.

The $d p r-G A L 4$ line, $d p r^{p \text { Gaw }}$, was generated by conversion of the original $P[l a c Z]$ element with a $P\left[G A L, w^{+}\right]$element using the targeted transposition strategy (Sepp and Auld, 1999). The fly stock used as the source of the $P\left[G A L, w^{+}\right]$element $(\mathrm{CyO}, P G a w)$ was obtained from $\mathrm{K}$. Ito (Department of Developmental Biology, National Institute for Basic Biology, Okazaki, Japan) and the Nippon consortium. To screen for successful P-element conversion, $d p r^{I R H} / \mathrm{CyO}, P G a w ; \Delta 2-3 /+$ flies were crossed with $U A S$-EGFP flies, and $\mathrm{Cy}^{+}$offspring were screened for green fluorescent protein (GFP) expression in the anterior wing margin. Insertion of the PGaw was confirmed by performing PCR and DNA sequencing of the genomic DNA. Seven lines contained a precise exchange of the $P G a w$ element for the P[lacZ]. dpr PGaw showed a similar proboscis extension reflex (PER) phenotype as observed in $d p r^{1 R H}$.

The $\mathrm{P}[U A S-d p r]$ transgenic flies were generated by subcloning the full coding region of $d p r$ into pUAST (Brand and Perrimon, 1993). Transgenic flies were generated according to established protocols (Rubin and Spradling, 1982; Spradling and Rubin, 1982).

The poxn $n^{70-28}$ flies were provided by Dr. Kimura (Awasaki and Kimura, 1997).

Proboscis extension response. The proboscis extension assay was performed as described by Deak (1976) with some modifications. Flies were starved overnight $(16 \mathrm{hr})$ in a glass bottle containing moist cotton wool. The flies were then lightly anesthetized with $\mathrm{CO}_{2}$ and mounted to an insect pin at the notum using a small drop of cyanoacrylate glue. After mounting, the flies were placed in a humid holding container for $1 \mathrm{hr}$ before testing. Before the experiment, the flies were satiated with water to exclude a behavioral response to water stimulation alone (Shiraishi and Tanabe, 1974). This was accomplished by allowing the flies to drink distilled water until no proboscis extension was elicited by water stimulation. Water satiation of the flies was subsequently checked frequently during the experiment. Flies were then tested for a PER by touching the labelum with one of several test solutions. The test solution was held to the appendage for $3 \mathrm{sec}$ or until the fly extended its proboscis. The fly was observed for an additional $27 \mathrm{sec}$. If at any time during the $30 \mathrm{sec}$ period the fly extended its proboscis, it was scored as giving a PER. Dethier et al. (1965) developed an arbitrary scale quantifying proboscis extension on a scale of 0 (proboscis completely retracted) to 6 (proboscis fully extended and labelar lobes flared). In our experiments, any extension to position 2 or farther was considered a PER. A period of 3 min was allowed between successive applications to avoid facilitation or adaptation of the response. After each application, the test stimulus was removed by touching the appendage with distilled water and drying it with a small piece of tissue paper.

RNA blots. Polyadenylated RNA was prepared from Canton S (wildtype) and $d p r^{I}$ flies, and $10 \mu \mathrm{g}$ of each sample was fractionated on $3 \%$ formaldehyde- $0.8 \%$ agarose gels as described previously (Nakamura et al., 1994). The RNAs were transferred to GeneScreen (PerkinElmer Life Sciences, Boston, MA) and probed with the $d p r$ c6705-6 cDNA labeled with ${ }^{32} \mathrm{P}$, and the filter was exposed for 2 weeks using Kodak XAR film (Eastman Kodak, Rochester, NY) and a DuPont Cronex Lightning Plus intensifying screen. The sizes of the $d p r$ mRNA, in kilobases, were estimated using an RNA size marker (Bethesda Research Laboratories, Bethesda, MD). To determine whether similar amounts of sample were loaded in each lane, the filters were reprobed with the rp49 gene.

Isolation and sequencing of cDNA and genomic DNAs. A $1.7 \mathrm{~kb}$ DNA sequence flanking the $5^{\prime}$ end of the $d p r 6705$ P-element was recovered by the plasmid rescue technique (Pirrotta, 1986). This fragment was used to screen and identify $\lambda 6705$ from a Charon4A genomic library (Maniatis et al., 1978). The position of the P-element insert in $\lambda 6705$ was determined by a combination of Southern blotting, PCR amplification of the genomic DNA, and DNA sequencing. A $3.1 \mathrm{~kb}$ Bam HI-XbaI $\lambda 6705$ fragment was used to screen an adult head $\lambda Z$ AP cDNA library. Multiple cDNAs were identified, the longest of which, c6705-6 $(3.25 \mathrm{~kb})$, was sequenced. We screened the Charon4A genomic library using the c6705-6 cDNA as a probe and obtained two additional genomic clones, $\lambda \mathrm{C} 39$ and $\lambda \mathrm{C} 2$. A Drosophila P1 clone (DS02462) that covered the entire $d p r$ coding region was obtained from the Berkeley Drosophila Genome Project (BDGP). The cytological position assigned to this $\mathrm{P} 1$ phage from the BDGP is 57B2-57B3.

Identification of the DPR-related proteins. The deduced amino acid sequences of DPR2-DPR20 (see Fig. 5) were identified by performing
Table 1. BDGP numbers, chromosomal map positions of the genes, and E values of the BLAST scores

\begin{tabular}{llll} 
Gene & BDGP \# & Chrom/map pos. & E value \\
\hline$d p r 2$ & AC007186 & II (32A) & $4 \mathrm{e}-56$ \\
$d p r 3$ & CG15379 & II (22C1) & $2 \mathrm{e}-55$ \\
$d p r 4$ & CG12593 & III (86E11-86E13) & $8 \mathrm{e}-50$ \\
$d p r 5$ & CG5308 & III (86E8-86E11) & $4 \mathrm{e}-46$ \\
$d p r 6$ & AE003550 & III (67C1-67C9) & $7 \mathrm{e}-43$ \\
$d p r 7$ & AE003844 & IV (101F1-102B8) & $1 \mathrm{e}-42$ \\
$d p r 8$ & CG5291 & I (12E6-12E8) & $4 \mathrm{e}-39$ \\
$d p r 9$ & CG12601 & III (88E2) & $4 \mathrm{e}-37$ \\
$d p r 10$ & CG14158 \& & III (67D1-67D2) & $2 \mathrm{e}-34$ \\
$d p r 11$ & AC006939 & III (83F) & $2 \mathrm{e}-30$ \\
$d p r 12$ & AC012387 & II (42A) & $7 \mathrm{e}-30$ \\
$d p r 13$ & AC005298 & II (55A2-55B2) & $3 \mathrm{e}-29$ \\
$d p r 14$ & CG10946 & I (7C6-7C8) & $2 \mathrm{e}-28$ \\
$d p r 15$ & CG10095 & III (87B3-87B4) & $9 \mathrm{e}-28$ \\
$d p r 16$ & CG12591 & III (82F1-82F3) & $3 \mathrm{e}-27$ \\
$d p r 17$ & CG14738 & III (87B2) & $5 \mathrm{e}-27$ \\
$d p r 18$ & CG14948 & I (14A6) & $1 \mathrm{e}-23$ \\
$d p r 19$ & AC007451 & II (31D1-31F4) & $7 \mathrm{e}-20$ \\
$d p r 20$ & CG12191 & III (61D4) & $1 \mathrm{e}-17$ \\
\hline
\end{tabular}

basic local alignment search tool (BLAST) (translated nucleotide database) searches of the BDGP database. The gene numbers were assigned in order of decreasing significance of the BLAST scores (E values). Table 1 lists the BDGP numbers, chromosomal map positions of the genes, and E values of the BLAST scores.

Preparation of anti-DPR antibodies. Two DPR glutathione $S$-transferase (GST) fusion proteins were generated using the vector pGEX-KG (Guan and Dixon, 1991): (1) a PCR fragment encoding residues 52-250 was inserted into the EcoRI and HindIII sites to create GST-DPR-S; and (2) a PCR fragment encoding residues 52-367 was inserted into the EcoRI and XhoI to create GST-DPR-L. The fusion proteins were partially purified by electroelution from SDSpolyacrylamide gels as described previously (Montell and Rubin, 1988) and introduced into rabbits (HRP Inc., Denver, PA). One of the two rabbits (\#2) injected with GST-DPR-L (fusion \#2) generated antiserum that specifically reacted against the bacterial DPR fusion protein. This crude antiserum was affinity purified as described previously (Pollard, 1984). Briefly, $0.3 \mathrm{ml}$ of the anti-DPR antiserum was absorbed onto nitrocellulose strips containing GST-DPR-L, and the antibodies were eluted with acetic acid, neutralized, and dialyzed. The final volume of affinity-purified anti-DPR antibodies was $1.5 \mathrm{ml}$.

Western blot analysis. Sixty adult fly heads were homogenized in $100 \mu \mathrm{l}$ of SDS sample loading buffer. The samples were boiled for $3 \mathrm{~min}$, and 15 $\mu \mathrm{l}$ of each sample solution was fractionated by SDS-PAGE and transferred to Immobilon (IPVH 304 FO; Millipore, Bedford, MA) membranes. The filters were blocked for $30 \mathrm{~min}$ at room temperature in $0.5 \%$ Boehringer Mannheim blocking reagent (catalog \#1096-176; Indianapolis, IN) diluted in Tris-buffered saline solution (TBS), pH 7.4, and then incubated overnight at $4^{\circ} \mathrm{C}$ with purified anti-DPR polyclonal antibody diluted 1:250 in TBS. The filters were then washed in TBS and incubated with anti-rabbit Ig HRP conjugate (NA9340; Amersham Biosciences, Arlington Heights, IL) diluted 1:2000. Signals were detected using the ECL Western blotting detection regent (RPN 2106; Amersham Biosciences) as described by the manufacturer.

Immunocytochemistry. Whole mounts of adult dissected thoracic ganglia and horizontal sections of adult frozen fly heads $(8-12 \mu \mathrm{m})$ were fixed in

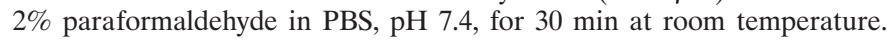
After several washes in TBS, the tissues were incubated overnight at $4^{\circ} \mathrm{C}$ with primary antibodies diluted in TBS containing $0.03 \%$ Triton X-100 and $5 \%$ fetal calf serum (or $0.5 \%$ Boehringer Mannheim blocking reagent for DPR antibody). After washing several times in TBS, the specimens were incubated with secondary antibodies for $40-60 \mathrm{~min}$ at room temperature diluted in the same buffer as for the primary antibodies. After several washes in TBS, Slow Fade (Molecular Probes, Eugene, OR) was added, and 
a coverslip was mounted. Confocal fluorescent images were obtained using a Zeiss (Oberkochen, Germany) LSM410 microscope. The antibodies were diluted as follows: affinity-purified anti-DPR rabbit polyclonal antibody, 1:50; $\beta$-galactosidase mouse monoclonal antibody (catalog \#Z3781; Promega, Madison, WI), 1:200; anti-embryonic lethal altered (ELAV) mouse monoclonal antibody mAb 9F8A9, 1:30 [gift from N. Patel (University of Chicago, Chicago, IL), originally generated by G. Rubin (University of California, Berkeley, Berkeley, CA)]; anti-rabbit FITC-conjugated IgG, 1:50 (catalog \#N1034, Amersham Biosciences); and anti-mouse rhodamine-conjugated IgG (catalog \#115-025-003 Jackson ImmunoResearch, West Grove, PA), 1:50.

5 -Bromo-4-chloro-3-indolyl- $\beta$-D-galactopyranoside staining. Two- to 4-d-old $d \mathrm{pr}^{1} / \mathrm{CyO}$ heterozygotes were used for all experiments. Staining of the adult visual system was performed using $8-12 \mu \mathrm{m}$ horizontal sections of adult frozen fly heads as described by Winberg et al. (1992). 5 -Bromo-4-chloro-3-indolyl- $\beta$-D-galactopyranoside (X-gal) staining on individual appendages was performed after dissection from flies in ice-cold PBS. To improve access of the fixative and staining solutions to the tissues, leg segments were cut into smaller pieces, and fine incisions were made in the wing margins. The isolated appendages were fixed in $1 \%$ glutaraldehyde in PBS for 20 min and rinsed three times in PBS. The appendages were transferred to a staining buffer (Hiromi et al., 1985) containing $0.1 \%$ Triton- $\mathrm{X}$ and incubated overnight at $37^{\circ} \mathrm{C}$. After the rinses, the appendages were mounted in $80 \%$ glycerol in PBS and examined at 10 -fold to 64 -fold magnification.

\section{RESULTS}

\section{Isolation of the taste mutant $d p r$}

The defective proboscis extension response ${ }^{1}\left(d p r^{1}\right)$ mutant was isolated from a collection of P-element insertion lines (line 6705; see Materials and Methods) and displayed a significant defect in salt but not sugar responsiveness. Canton $\mathrm{S}$ flies (a wild-type strain) respond to a test solution containing sucrose by extension of the proboscis and intake of the sugar (Falk and Atidia, 1975; Arora et al., 1987). Application of sucrose to the labelum induced a PER in a concentration-dependent manner (Fig. $1 A$ ). At the highest concentration of sucrose tested $(0.1 \mathrm{M}), \sim 80-90 \%$ flies tested exhibited a PER (Fig. $1 A$ ). During addition of salt to the test solution, the sucrose-induced PER was inhibited (Fig. 1B). The extend of this inhibition was proportional to the concentration of $\mathrm{NaCl}$. Only $\sim 30 \%$ of wild-type flies displayed a PER in the presence of $1 \mathrm{M} \mathrm{NaCl}$ and $0.1 \mathrm{M}$ sucrose (Fig. $1 B, C$ ) (Falk and Atidia, 1975; Arora et al., 1987). This represents a suppression of $\sim 2.7$-fold to 3-fold at the highest concentrations of $\mathrm{NaCl}$.

In contrast to wild-type flies, we found that $d p r^{1}$ homozygotes showed a significant reduction in salt-mediated suppression of the sugar response. The proportion of $d p r^{1}$ homozygotes that extended their probosces in response to sucrose alone was similar to wild type over a 10,000-fold range of sucrose concentrations (Fig. $1 A$ ). However, in contrast to the wild-type response to sucrose, which was suppressed $\sim 2.7$-fold to 3 -fold by $1 \mathrm{M} \mathrm{NaCl}$, the $d p r^{1}$ PER was reduced only slightly. Addition of $1 \mathrm{M} \mathrm{NaCl}$ to the test solution resulted in a reduction of the $d p r^{1}$ PER of only $\sim 1.3$-fold reduction (Fig. $1 B, C$ ). These results indicate that the $d p r^{1}$ mutation affected the salt aversion response but not the response to sucrose. The $d p r^{1}$ mutation was recessive, because $d p r^{1} /+$ flies exhibited a normal salt aversion response (data not shown).

The reduction in salt responsiveness, observed in $d p r^{1}$ homozygotes, also appeared to occur in combination with two other sugars tested, glucose and fructose. The percentage of $d p r^{1} /+$ and $d p r^{l}$ flies that elicited a PER was similar in the presence of glucose alone $(0.1 \mathrm{M})(83 \pm 16 \%, n=24$ and $84 \pm 15 \%, n=28$, respectively). However, in the presence of glucose plus $1 \mathrm{M} \mathrm{NaCl}$, $d p r^{1} /+$ flies showed a suppression of $\sim 2.5$-fold $(83 \pm 16 \%, n=24$ vs $33 \pm 26 \%, n=24)$, whereas the reduction in $d p r^{1}$ flies was $\sim 1.6$-fold ( $84 \pm 15 \%, n=28$ vs $51 \pm 30 \%, n=28$, respectively).
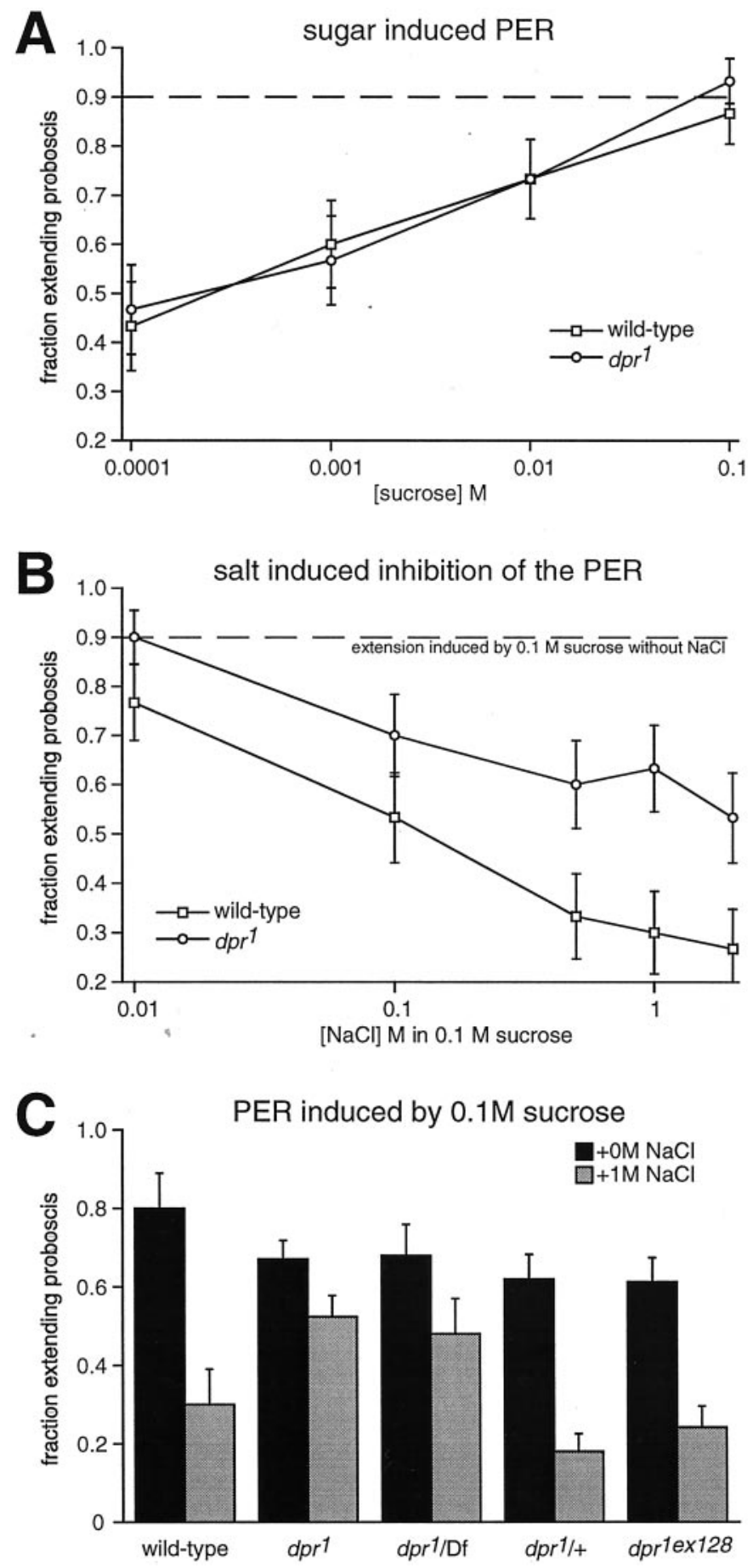

Figure 1. Proboscis extension response assay. $A$, The fraction of flies extending their proboscis in response to presentation of a solution containing different concentrations of sucrose. The wild-type (Canton S) and $d r^{l}$ responses are indicated by the squares and circles, respectively. The SEMs, indicated by the error bars, were based on samples of 29-32 flies. $B$, The fraction of flies exhibiting a PER during exposure to $0.1 \mathrm{M}$ sucrose and varying concentrations of $\mathrm{NaCl}$. Mean results were compiled from analyses of 29-32 flies. $C$, Proportion of flies extending their proboscis in response to either $0.1 \mathrm{M}$ sucrose (black columns) or $0.1 \mathrm{M}$ sucrose in combination with $1 \mathrm{M} \mathrm{NaCl}$ ( gray columns). The following stocks were analyzed: wild type (Canton S), $d p r^{1}$ homozygotes $\left(d p r^{1}\right), d p r^{1}$ in trans with a deficiency, Df(2R)AA21, which uncovers $d p r^{1}$ (dpr $r^{1}$ Df), and an excision allele of $d p r^{l}\left(d p r^{\text {lex128 }}\right)$. Twenty to 32 flies were analyzed for each stock. 
Both $d p r^{1} /+$ and $d p r^{1}$ flies displayed nearly identical PERs to fructose alone $(0.1 \mathrm{M})(74 \pm 21 \%, n=24$ and $74 \pm 19 \%, n=28$, respectively), although the responses was slightly lower than with glucose or sucrose. However, $1 \mathrm{~m} \mathrm{NaCl}$ caused a greater suppression of the fructose-induced response in $d \mathrm{pr}^{1} /+(>2.2$-fold $)(74 \pm$ $21 \%, n=24$ and $33 \pm 23 \%, n=24$, respectively) than in $d p r^{1}$ flies (1.6-fold) $(74 \pm 19 \%, n=28$ and $46 \pm 29 \%, n=28$, respectively). Thus, the defect in salt-induced suppression of the PER in $d p r^{1}$ did not appear to be specific to sucrose.

The defect in the salt response in $d p r^{1}$ appeared to be attributable to the lac $Z$ reporter P-element (Karpen and Spradling, 1992), which inserted at 57B1-3. Flies containing the P-element in trans with a deficiency that spanned the insertion site showed reduced salt-induced suppression of the sugar response similar to the $d p r^{1}$ homozygote (Fig. $1 C$ ). Furthermore, during mobilization of the P-element, a wild-type salt response was detected in seven of nine excision lines tested (Fig. $1 C, d p r^{1 e x 128}$ ).

\section{dpr reporter expression associated with chemosensory sensilla}

In the adult fly, taste organs are distributed in sensory organs (sensilla) on several body parts, including the labelum, legs, and wings (Stocker, 1994). To determine the presumptive spatial distribution of $d p r$ in the adult fly, we first examined the expression of the lacZ reporter gene within the P-element in $d p r^{1} /+$ heterozygotes by staining either for $\beta$-galactosidase activity (lac $Z$ activity) or using anti- $\beta$-galactosidase antibodies. $\beta$-Galactosidase was restricted to the nucleus because it was expressed as a fusion protein that contained a nuclear localization sequence (Karpen and Spradling, 1992).

We found that $d p r$ reporter expression was associated with chemosensory (taste) and not mechanosensory organs. The chemosensory and mechanosensory organs on the wings and legs can be distinguished by the morphology of the bristles associated with each type of sensillum. The mechanosensory bristles are straight or gently curved and taper to a sharp point, whereas the chemosensory bristles are recurved and have a blunt tip attributable to the presence of a terminal transcuticular pore. On the anterior wing margins, there are three rows of bristles (Palka et al., 1979; Hartenstein and Posakony, 1989), and the taste bristles are situated in the dorsal and ventral rows (Fig. 2B,C, red and green arrows, respectively). We found that staining was associated with the bases of the recurved, blunt chemosensory bristles on the wings and the legs, whereas the bases of the mechanosensory bristles were unstained (Fig. $2 A$ ). In addition, staining was detected in the labial palps, which are the main taste organs situated near the distal end of the proboscis (Fig. 2D).

In addition to the gustatory bristles, $d p r$ reporter expression was detected in other sensory neurons, such as photoreceptor cells and olfactory cells, and in neurons in the CNS. Adult Drosophila bear olfactory sensilla on the third segment of the antennae and on the maxillary palps. lac $Z$ activity was not seen in the olfactory segment of the antenna but was present in the maxillary palp (data not shown). Expression of $l a c Z$ was observed in neuronal nuclei of the thoracic ganglion, brain, and optic lobes (Fig. $2 H-M)$. The cells expressing the $\beta$-galactosidase were a subset of cells stained with antibodies to the pan-neuronal marker ELAV (Robinow and White, 1991) (Fig. 2I-M). Thus, $d p r$ was expressed in a subset of neurons in the CNS. In the retina, the only lacZ-positive nuclei were situated in the proximal region closest to the lamina, a pattern consistent with a subset of R8 cells (Fig. 2I). No other retinal cells, including photoreceptor cells
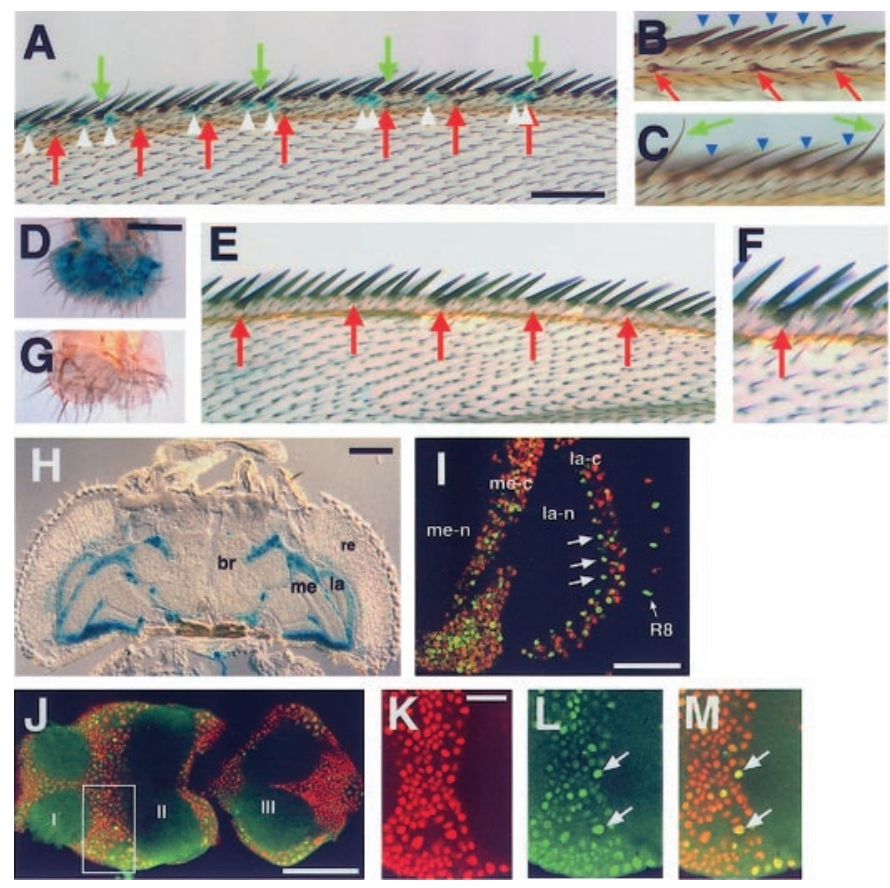

Figure 2. Expression of the $d p r$ lac $Z$ reporter. $A-D$ and $H-M$ show staining in $d p r^{1} /+$ flies. $E-G$ show the results of lac $Z$ staining in $p o x n^{70-28}$, $d p r^{1} / p x^{70-28}$ flies. $A$, Anterior wing margin. Cells that display lac $Z$ activity are indicated with white arrowheads. The positive cells are situated at the bases of both dorsal (red arrows) and ventral (green arrows) chemosensory bristles. $B$, Dorsal and medial rows of wing sensory bristles. Chemosensory bristles (red arrows) and mechanosensory bristles (blue arrowheads) are indicated. $C$, Ventral view of chemosensory sensilla with recurved bristles (indicated by arrow). The recurved bristles are separated by several mechanosensory bristles (blue arrowheads). D, Tip of the labelum showing strong $l a c Z$ staining. $E$, No lac $Z$ staining in the anterior wing margin of $\operatorname{poxn}^{70-28}, \mathrm{dpr}^{1} / \mathrm{poxn}^{70-28}$ flies. The transformed bristles are indicated by the red arrows. F, Magnification of the transformed bristles (red arrow) in poxn ${ }^{70-28}$, dpr $^{1} /$ poxn $^{70-28}$ flies stained for lacZ activity. $G$, Tip of the labelum did not show staining in $p o x n^{70-28}, d p r^{1} /$ poxn ${ }^{70-28}$ flies. $H$, Horizontal section of an adult fly head stained for lac $Z$ activity. $b r$, Brain; $l a$, lamina; $m e$, medulla; $r e$, retina. $I$, Proximal region of the optic lobe and retina stained with anti- $\beta$-galactosidase (green) and anti-ELAV (red) antibodies. In the lamina cell layer, there were typically two $d p r$-positive cells in a single laminal cartridge (indicated by arrows). In the retina, staining was restricted to the R8 photoreceptor cells (indicated with the small arrow). la-c, Lamina cell body region; la- $n$, lamina neuropil region; me-c, medulla cell body region; $m e-n$, medulla neuropil region; $R 8$, nucleus of an R8 cell. $J$, Optical horizontal section of the ventral region of the adult thoracic ganglion stained with anti- $\beta$ galactosidase (green) and anti-ELAV (red) antibodies showing the first (I), second (II), and third (III) segments. The box indicates a region shown at higher magnification in $K-M$. $K$, Anti-ELAV. $L$, Anti- $\beta$ galactosidase. $M$, Merged images of the anti-ELAV and anti- $\beta$ galactosidase staining. Indicated with arrows are examples of cells showing very intense anti- $\beta$-galactosidase staining. Scale bars: $A, D, J, 50 \mu \mathrm{m}$; $H, 100 \mu \mathrm{m} ; I, 25 \mu \mathrm{m} ; K, 10 \mu \mathrm{m}$.

R1-R7, expressed lacZ. In addition, there was significant lacZ activity and anti- $\beta$-galactosidase staining in the optic lobes (Fig. 2 $H, I)$. However, there was no obvious defect in the $d p r$ visual response, because $d p r$ mutant flies displayed normal phototaxis and the electroretinogram recording was indistinguishable from wild type (data not shown).

To obtain additional evidence that the $d p r$-expressing cells are associated with chemosensory bristles, it would be useful to determine whether the neuronal processes extend into the sensory bristles. However, the $\beta$-galactosidase reporter was restricted 

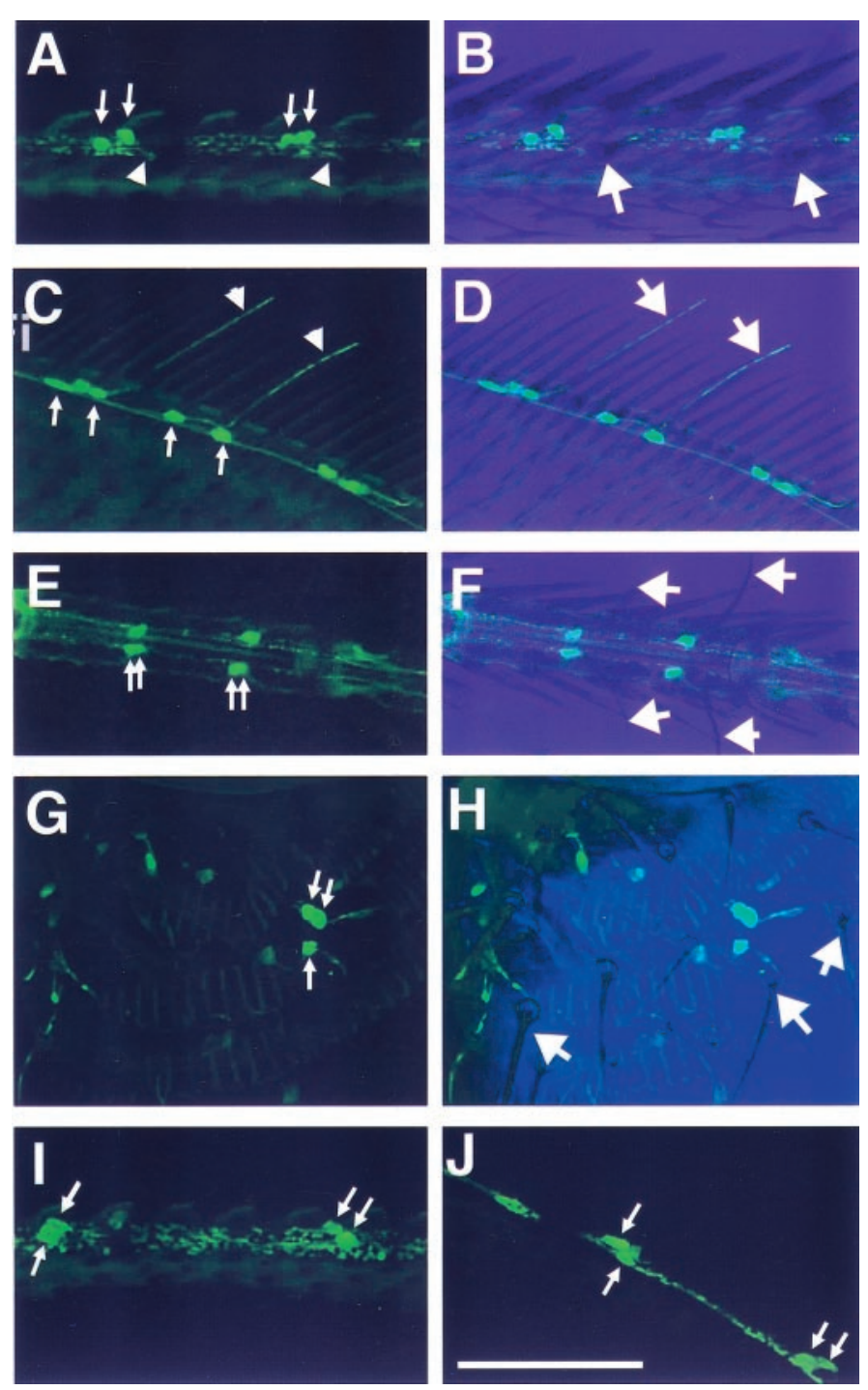

Figure 3. Distribution and morphology of $d p r$-expressing cells examined using GFP. The GFP was expressed using the GAL4/UAS system and examined by confocal microscopy. $A-H$, GFP expression in $d p r^{+} / d p r$ heterozygous flies $(d p r-G A L 4, U A S-d p r /+)$. I, J, GFP expression in $d p r$ homozygous flies (dpr-GAL4, UAS-dpr/dpr ${ }^{I R H}$ ). Tissues are oriented with the distal side to the right, except in $G$ and $H$. Scale bar: $A-J, 50 \mu \mathrm{m} . A$, Anterior wing margin. Two pairs of cells showing strong GFP staining (indicated by small arrows). The arrowheads indicate dendrites extending from the cell bodies to the base of chemosensory bristles. $B$, Merge of GFP (shown in $A$ ) with the Nomarski image. The large arrows indicate the bases of chemosensory bristles. No GFP expression was evident at the bases of the mechanosensory bristles. $C$, Distal region of the anterior wing margin. GFP staining was observed in pairs of cells (small arrows) and in hair shafts (large arrowheads); the spatial relationship of neuronal cell bodies and their corresponding hair shafts is evident. $D$, Merge of GFP (shown in $C$ ) with the Nomarski image. The large arrows indicate GFP staining in hair shafts. $E$, Ventral view of the third tarsal leg segment. GFP-positive clusters each contain two neurons (arrows). $F$, Merge of GFP (shown in $E$ ) with the Nomarski image. Each GFP-positive pair of neurons was near the base of a recurved bristle, indicated by a large arrow. $G$, GFP-positive neurons in the proboscis occur singly or in groups of two (indicated by small arrowheads). $H$, Merge of GFP (shown in $G$ ) with Nomarski image. Chemosensory bristles (arrows) are innervated by GFPpositive neurons. I, Anterior wing margin in a $d p r$ homozygote. $J$, Distal region of anterior wing margin in a $d p r$ homozygote. to the nucleus and did not stain neuronal processes. Therefore, we expressed a cytoplasmic marker, the GFP, in $d p r$-positive cells using the GAL4/UAS system (Brand and Perrimon, 1993). To generate a $d p r-G A L 4$ line for directing expression of $U A S-G F P$, we replaced the $d p r-P[$ lacZ $]$ enhancer trap with a $P[G A L 4]$ element according to the P-element substitution technique (Sepp and Auld, 1999).

We found that the GFP expressed in $\operatorname{dpr}-G A L 4, U A S-G F P /+$ flies showed a pattern of distribution similar to that of the $l a c Z$ reporter. GFP-positive neurons in the anterior wing margin (Fig. $3 A--D$ ) and legs (Fig. $3 E, F$ ) occurred in pairs, although some single GFP-positive neurons were detected in the labelum (Fig. $3 G, H)$. Of significance here, many dendritic processes could be traced from these GFP-positive neurons to the bases of chemosensory bristles and, in some cases, all the way to their tips (Fig. $3 C, D)$. The numbers and morphology of GFP-positive neurons in dpr-GAL4, UAS-GFP homozygotes (Fig. 3I,J) were similar to the $d p r-G A L 4, U A S-G F P /+$ heterozygotes. Given that the $d p r-G A L 4$ homozygotes displayed the same defect in the salt aversion response as the $d p r^{1}$ flies (data not shown), these data suggest that the $d \mathrm{pr}^{1}$ mutation did not eliminate or disrupt the gross morphology of those cells that express $d p r$. Evidence that the $d p r l a c Z$ and GFP reporters reflect the expression pattern of the DPR protein is presented below, using anti-DPR antibodies.

Finally, to confirm that the $d p r$ reporter expression was detected in the chemosensory bristles, we followed a genetic approach that was used recently to demonstrate that candidate taste receptors are expressed in chemosensory bristles (Clyne et al., 2000; Dunipace et al., 2001). This strategy took advantage of a mutation in the pox-neuro (poxn) locus, which results in the conversion of the recurved chemosensory bristles, such as those near the wing margins, into the more stout and straight mechanosensory bristles (Awasaki and Kimura, 1997). We found that the $l a c Z$ staining was absent from the anterior wing margins and dramatically reduced near the distal end of the proboscis in flies homozygous for the poxn mutation and heterozygous for $d p r^{1}$ $\left(\right.$ poxn $^{70-28}, \mathrm{dpr}^{1} /$ poxn $^{70-28}$ ) (Fig. $\left.2 F, G\right)$. These results were not attributable to a general problem in lac $Z$ staining in poxn $^{70-28}$, $d p r^{1} / p o x n^{70-28}$ flies, because the level of lac $Z$ staining in the CNS was similar to that observed in $d p r^{1} /+$ flies (data not shown).

\section{Identification of the dpr mRNA}

$d p r^{1}$ flies contained a single P-element, as determined by Southern blot analysis, which mapped to 57B1-3 on salivary gland polytene chromosomes (data not shown). To clone the $d p r$ gene, we isolated genomic DNA flanking the P-element insertion site by the plasmid rescue technique. A $3.5 \mathrm{~kb}$ genomic sequence was obtained and used as a probe for screening genomic libraries. Several phage clones were subsequently isolated and used to generate a physical map (Fig. 4A). The genomic sequences released recently by Celera and the BDGP (Adams et al., 2000) were consistent with this physical map.

To identify a candidate $d p r$ mRNA, DNA sequences flanking both sides of the P-element were used to screen cDNA libraries. Several related cDNAs were identified using genomic DNA adjacent to the $5^{\prime}$ end of the P-element. The longest cDNA, c6705-6, was $3.25 \mathrm{~kb}$ and contained a complete open reading frame. The c6705-6 mRNA encoded eight exons spanning a $35 \mathrm{~kb}$ genomic region (Fig. $4 A$ ).

Four lines of evidence indicated that $d p r$ was encoded by the $3.25 \mathrm{~kb}$ c6705-6 cDNA. First, the P-element insertion site was 23 nucleotides $5^{\prime}$ to the end of the $6705-6$ cDNA. Because the 

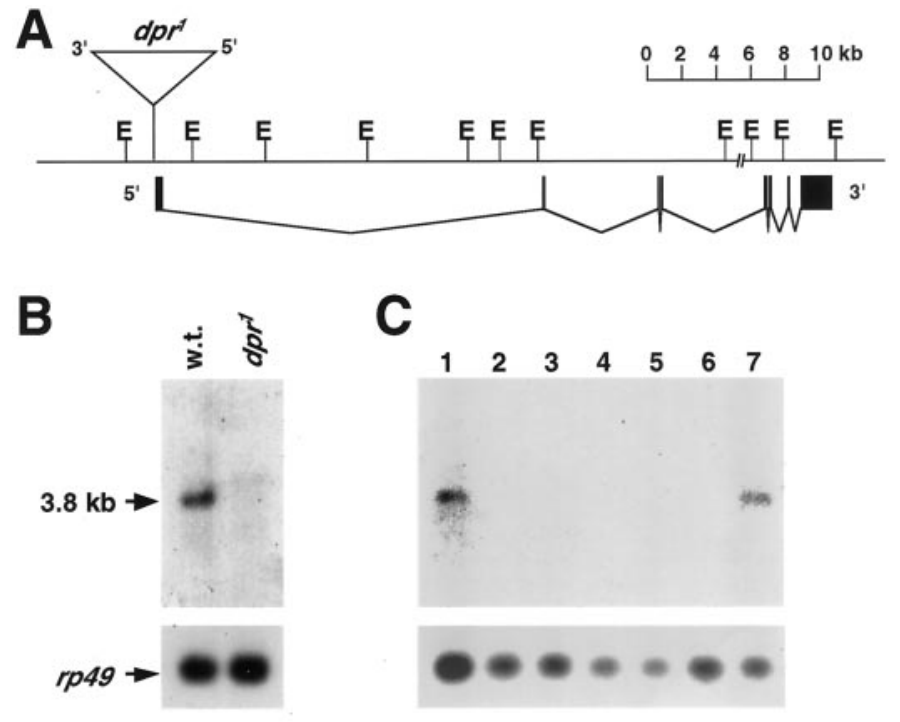

D

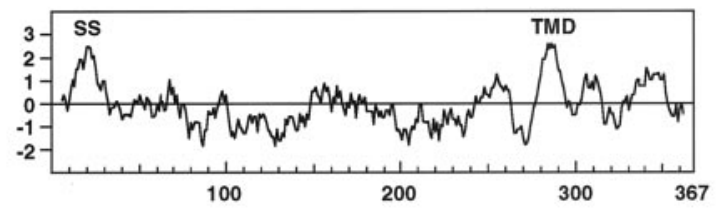

E

\begin{tabular}{|l|l|l|l|l|l|}
\hline SS & Ig-I & & Ig-II & TMD \\
\hline
\end{tabular}

Figure 4. Molecular analysis of the $d p r$ gene. $A$, Genomic region flanking the P-element insertion site. The positions of EcoRI $(E)$ sites are shown. The P-element is represented by the large inverted triangle. The site of insertion of the P-element is indicated by the vertical line connecting the inverted triangle to the genomic DNA. The orientation of the 5' and $3^{\prime}$ ends of the P-element is indicated. The $d p r$ exons, deduced by comparison of the cDNA and genomic sequences, are indicated by the black boxes below the genomic map. $B$, Expression of $d p r$ RNA in wild type and $d p r^{1}$. Ten micrograms of wild-type (w.t.) and $d p r^{1}$ polyadenylated RNA were fractionated on $3 \%$ formaldehyde $-0.8 \%$ agarose gels, transferred to membranes, and probed with the c-6705-6 cDNA labeled with ${ }^{32} \mathrm{P}$. Filters were reprobed with rp49 to ascertain whether the RNAs were comparably loaded in each lane. $C$, Developmental expression of $d p r$ mRNA. Polyadenylated RNA was prepared after collecting embryos for $4 \mathrm{hr}$ from the Canton S (wild-type) strain and incubating at $25^{\circ} \mathrm{C}$ for either $0-16 \mathrm{hr}$ (0-20 hr embryos) or for 1, 2, 4, 6, 8, and 9-10 d (adults). The 1, 2, and $4 \mathrm{~d}$ collections coincided approximately with the first, second, and third instar larval stages, and the 6 and $8 \mathrm{~d}$ collections corresponded approximately with the early and late pupal stages. Lanes were loaded as follows: lane 1, embryo RNA; lanes 2-6, contained RNA from samples prepared after 1, 2, 4, 6, and 8 d of development, respectively; lane 7, adult RNA. The size of the $3.8 \mathrm{~kb}$ mRNA was estimated based on the migration of RNA size markers. $D$, Hydrophobicity analysis of DPR (Kyte and Doolittle, 1982). The putative signal sequence (SS) (Nielsen et al., 1997) and the transmembrane domain (TMD) (Kyte and Doolittle, 1982) are indicated. $E$, Schematic of the domain organization of DPR. SS, N-terminal signal sequence; $I g-I$ and $I g-I I$, the two Ig domains; TMD, transmembrane domain.

c6705-6 cDNA was $\sim 0.5 \mathrm{~kb}$ shorter than the 6705 RNA and the c6705-6 cDNA contained a poly $\left(\mathrm{A}^{+}\right)$tail, it appeared that the cDNA was truncated at the $5^{\prime}$ end. Thus, the P-element may have inserted into an intron or exon in the $5^{\prime}$ untranslated region. Second, we probed poly $\left(\mathrm{A}^{+}\right)$RNA prepared from wild-type and $d p r^{1}$ adults with the $3.25 \mathrm{~kb}$ cDNA and identified a single $3.8 \mathrm{~kb}$ mRNA in wild-type that was not observed in $d p r^{1}$ (Fig. $4 B$ ). In addition, a very weak RNA band of larger molecular weight was reproducibly detected in $d p r^{1}$ that was not observed in wild type (Fig. 4B). Third, the concentration of the 6705-6 protein was dramatically reduced and was barely detectable in $d p r^{l}$ (see below). Fourth, the $d p r^{1}$ phenotype was rescued in transgenic flies expressing the c6705-6 cDNA (dpr-GAL4; UAS-dpr). As expected, a similar proportion of $d p r-G A L 4 ; U A S$ - $d p r$ and wild-type flies displayed a PER during exposure to $0.1 \mathrm{M}$ sucrose alone $(80 \pm 17 \%, n=35$ and $76 \pm 15 \%, n=28$, respectively). More importantly, nearly indistinguishable proportions of $d p r-G A L 4$; $U A S$ - $d p r$ and wild type extended their probosces in response to a test solution containing both $0.1 \mathrm{M}$ sucrose and $1 \mathrm{M} \mathrm{NaCl}$ (34 \pm $23 \%, n=35$ and $32 \pm 19 \%, n=28$, respectively).

Expression of $d p r$ during the course of development was determined by probing an RNA blot containing $\operatorname{poly}\left(\mathrm{A}^{+}\right)$RNA prepared during various stages of development. We found that $d p r$ was expressed at the highest levels in the adult and in embryos (Fig. $4 C$ ). However, we could not exclude that the $d p r$ RNA was expressed at lower levels during larval and pupal development because we were not able to detect levels of $d p r$ mRNA expression significantly lower than those shown (Fig. 4C). Detection of the $d p r$ signals detected in the embryos and adults required long exposure times with relatively large concentrations of poly $\left(\mathrm{A}^{+}\right)$ RNA (see Materials and Methods).

\section{dpr encodes a member of the Ig superfamily}

The $d p r$ cDNA contained a single large open reading frame of 367 amino acids. Analysis of the deduced amino acid sequence, according to the Kyte and Doolittle algorithm (Kyte and Doolittle, 1982), suggested that DPR has two membrane-spanning domains (Fig. 4D). The hydrophobic region near the $\mathrm{N}$ terminus was predicted by the method of von Heijne to be a signal sequence with a cleavage site after residue 32 (Fig. 4D) (Nielsen et al., 1997). Thus, the DPR protein was predicted to consist, after cleavage, of an extracellular domain of $\sim 245$ amino acids, a single transmembrane domain (residues 276-293), and an intracellular domain of $\sim 75$ amino acids (Fig. $4 D$ ).

Comparison with the protein databanks indicated that DPR contained two Ig motifs (Fig. $4 E$ ). Three types of Ig domains have been described $(\mathrm{V}, \mathrm{C} 1$, and $\mathrm{C} 2)$, based on the number of anti-parallel $\beta$-sheets, the distance between the conserved cysteine residues, and characteristic residues conserved within each class (Williams and Barclay, 1988; Brümmendorf and Rathjen, 1995). The first Ig domain in DPR (Ig-I; amino acids 71-141) contained features similar to V-and C2-type domains, whereas the second Ig domain (Ig-II; amino acid 174-247) most resembled the $\mathrm{C} 2$ class. These domains display similarity to a variety of proteins in vertebrates and invertebrates that are known to function or are expressed in the nervous system. These include Lachesin (Karlstrom et al., 1993), a protein originally identified in the grasshopper, the Drosophila Klingon protein (Butler et al., 1997), and the mammalian protein LAMP (limbic systemassociated membrane protein) (Pimenta et al., 1995). Similarity was also found to many neural adhesion molecules, such as mouse N-CAM (Hemperly et al., 1986) and L1 (Moos et al., 1988). However, the DPR Ig domains share $\leq 25 \%$ amino acid identity to Ig domains of these proteins.

Many molecules containing Ig domains also contain one or more type III fibronectin repeats, a motif 90 amino acids long that occurs many times in the extracellular adhesive protein fibronectin (Brümmendorf and Rathjen, 1993). The region of DPR $\mathrm{N}$ terminal to the Ig domains was most related to five small fragments of type III fibronectin repeats. However, the first and 
A
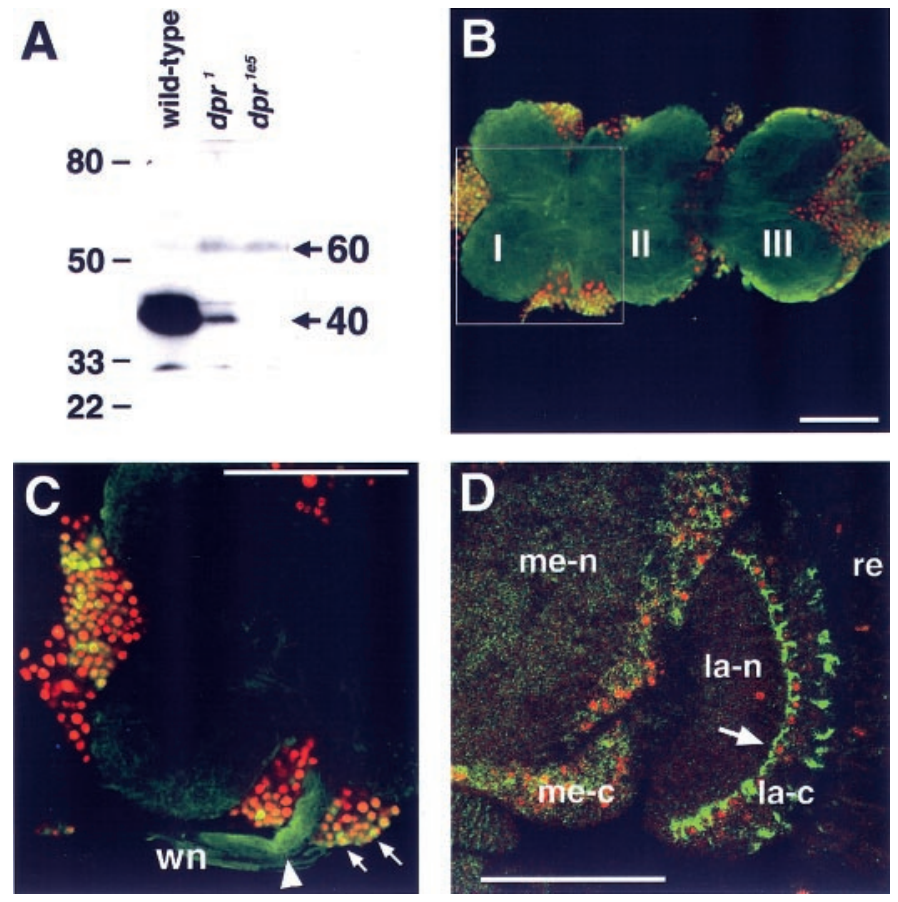

Figure 5. Expression of the DPR protein. A, Western blot of the DPR protein. Extracts from wild type, $d p r^{l}$, and $d p r^{l e 5}$ were fractionated by SDS-PAGE, transferred to a membrane, and probed with the polyclonal anti-DPR antibody. The positions of protein size markers and the $40 \mathrm{kDa}$ DPR band is indicated to the left and right, respectively. B, Spatial distribution of DPR in an optical horizontal section of a $d^{-} r^{+}$thoracic ganglion. Anti-DPR staining is shown in green, and neuronal nuclei are labeled with anti-ELAV antibody (red). The first $(I)$, second $(I I)$, and third (III) segments of the thoracic ganglion are indicated. $C$, Enlarged portion of $B$, indicated by the white box. DPR expression is detected in a subset of neural cell bodies, some of which are indicated with arrows. A bundle of the wing nerve $(w n)$ also shows a relatively high level of anti-DPR staining (indicated with the arrowhead). $D$, Horizontal section of adult head $\left(\mathrm{dpr}^{1} /+\right)$ double stained with anti-DPR antibodies ( green) and anti- $\beta$-galactosidase antibodies (red). The proximal region of the laminal cell layer showed a high level of anti-DPR staining (indicated with an arrow). la-c, Lamina distal region (containing cell bodies); la- $n$, lamina proximal region (neuropil); $m e-c$, medulla distal region (containing cell bodies); $m e-n$, medulla proximal region (neuropil); re, retina. Scale bars: $B-D, 50 \mu \mathrm{m}$. It was not possible to determine the distribution of the DPR protein in the appendages because the cuticle prevented penetration of the antibodies.

part of the second type III fibronectin repeat fragments are predicted to be eliminated by cleavage of the putative signal sequence. The $\sim 75$ amino acid C-terminal domain, which is predicted to be intracellular, does not share significant homology with other proteins in the databanks.

\section{Expression of the DPR protein}

To identify the DPR protein on Western blots and confirm the spatial localization pattern predicted by the lac $Z$ and GFP expression patterns, we raised polyclonal antisera to a glutathione $S$-transferase-DPR fusion protein containing DPR amino acids 52-367 (see Materials and Methods). Extracts were prepared from wild-type fly heads, fractionated by SDS-PAGE, and probed with the anti-DPR antibodies. We found that DPR migrated as a $40 \mathrm{kDa}$ protein, the size predicted for the unmodified full-length protein (Fig. 5A). DPR would be predicted to be $37 \mathrm{kDa}$ after cleavage of the putative signal sequence after residue 32 . However, the migration of DPR might be retarded by sugar modifi- cation because it is predicted to contain five N-linked glycosylation sites (residues 62, 119, 175, 240, and 269).

Expression of the $40 \mathrm{kDa}$ DPR protein was dramatically decreased but not eliminated in $d p r^{1}$ flies (Fig. 5A). Therefore, to obtain a $d p r$ allele that did not express any $40 \mathrm{kDa}$ protein, we attempted to delete a portion of the protein coding region by imprecise excision of the P-element present in $d p r^{1}$ flies (see Materials and Methods). One excision allele, which lacked $\sim 0.2$ $\mathrm{kb}$ of genomic DNA flanking the $3^{\prime}$ end of the inserted P-element $\left(d p r^{1 e 5}\right)$, did not express a detectable level of the $40 \mathrm{kDa}$ DPR protein (Fig. 5A).

To examine the spatial distribution of the DPR protein, we stained dissected thoracic ganglia and adult head sections with the anti-DPR antibodies (Fig. 5B--D). To identify neurons, the tissue was also stained with antibodies to the pan-neuronal marker ELAV. In the lateral thoracic ganglion region, in which the wing chemosensory neurons synapse, DPR appeared to localize to the cell bodies of a subset of neurons (Fig. 5C). DPR was also detected in the bundle of the wing nerve (Fig. $5 C$ ). It was not possible to assess the localization of DPR in the peripheral chemoreceptors because these neurons failed to stain with antibodies to either the pan-neural marker ELAV or to DPR.

In the adult head, the most prominent anti-DPR staining was in neuronal cell bodies in the laminar and medullar regions of the optic lobes. Moreover, the staining appeared to be in the plasma membrane, as might be expected given that DPR contains a putative signal sequence and a transmembrane domain. DPR was also expressed in the neuropilar portions of the optic lobes containing axons and synapses (Fig. 5D).

\section{A family of DPR-related proteins}

A scan of the Drosophila sequence databank (BDGP) with DPR revealed 19 independent sequences with significant similarity to both Ig domains of DPR (DPR2-19) (Fig. 6). None of these sequences corresponded to genes or proteins that have been characterized previously. The percentage of identities between the original family member, DPR1, and the related sequences, DPR2-20, were 30-52\% and encompassed nearly the entire extracellular domain. The region of similarity initiated 22 residues after the putative cleavage site and continued to within 19 residues of the predicted transmembrane domain. In several sequences, the homology extended nearly to the transmembrane domain (DRR4, DRP5, DPR14, and DPR18). In most cases, cDNA sequences were either unavailable or were incomplete, and the amino acid sequences were deduced from the genomic DNA. However, a complete cDNA sequence was available for DPR5. This putative protein had several features similar to DPR1. These included two Ig domains, a predicted N-terminal cleavage site, and a single membrane-spanning domain. DPR5 contained a short predicted intracellular domain of 13 residues; however, it did not bear sequence similarity to DPR1.

Members of the $d p r l$ family that were most related tended to be clustered at similar chromosomal map positions. The three most salient examples were the pairs: dpr4/dpr5, dpr6/dpr10, and dpr15/ $d p r 17$ (Fig. $7 A, B$ ). In addition, $d p r 11$ and $d p r 16$, which flanked $d p r 15$ and $d p r 17$ in the dendrogram, formed a looser cluster with this latter pair (Fig. 7 $A, B$ ). Other $d p r$ genes that fell on the same or adjacent branches of the phylogenetic tree, but were not clustered, typically mapped to the same chromosome. These included dpr1/dpr2/dpr3 and dpr12/dpr13/dpr19. 

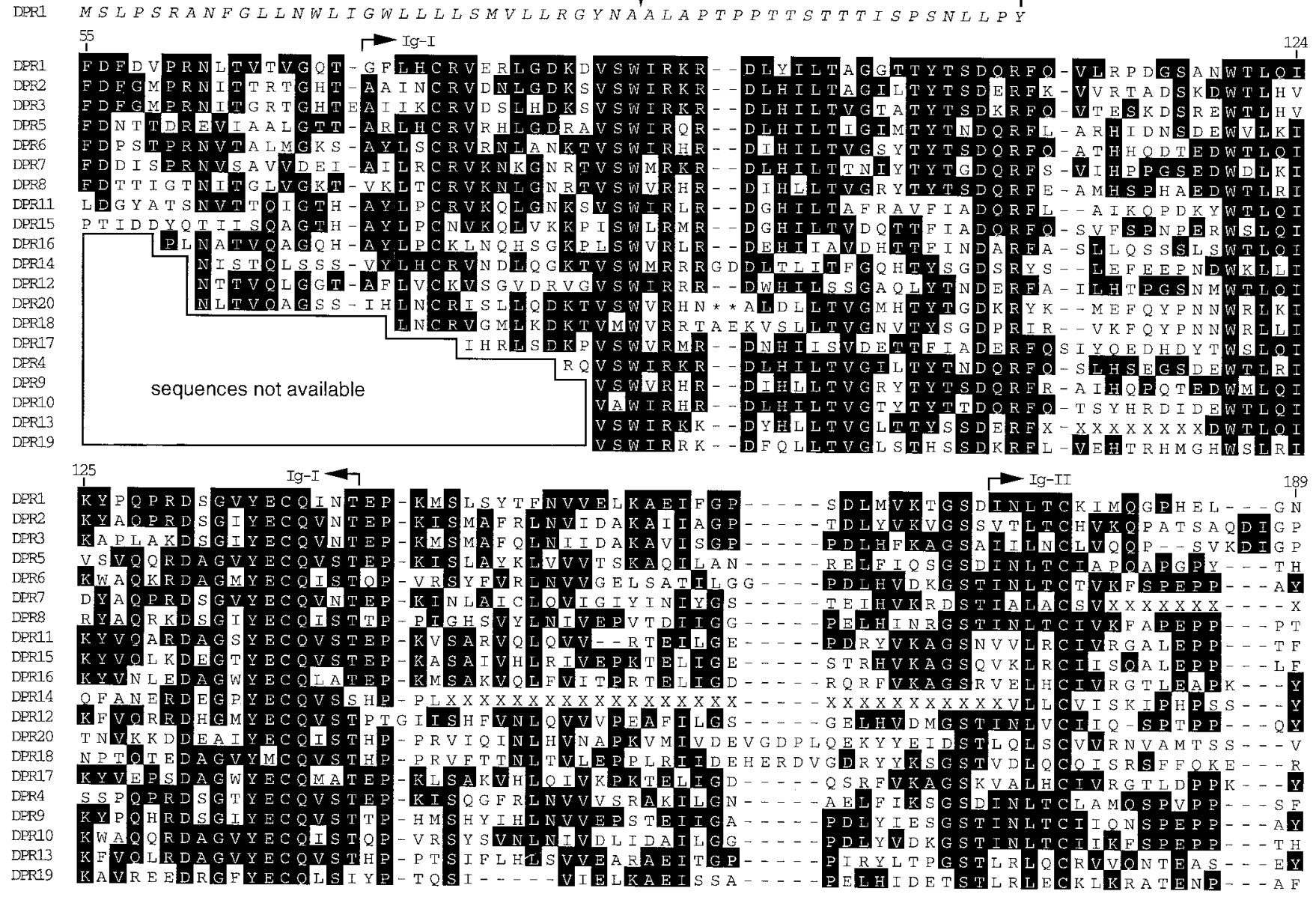

$\begin{array}{ll} & 190 \\ \text { DPR1 } & \text { I } \\ \text { DPR2 } & \text { I } \\ \text { DPR3 } & \text { I } \\ \text { DPR5 } & \text { M } \\ \text { DPR6 } & \text { I } \\ \text { DPR7 } & \text { X } \\ \text { DPR8 } & \text { V } \\ \text { DPR11 } & \text { I } \\ \text { DPR15 } & \text { I } \\ \text { DPR16 } & \text { I } \\ \text { DPR14 } & \text { I } \\ \text { DPR12 } & \text { V } \\ \text { DPR20 } & \text { V } \\ \text { DPR18 } & \text { I } \\ \text { DPR17 } & \text { I } \\ \text { DPR4 } & \text { I } \\ \text { DPR9 } & \text { I } \\ \text { DPR10 } & \text { I } \\ \text { DPR13 } & \text { I } \\ \text { DPR19 } & \text { V }\end{array}$

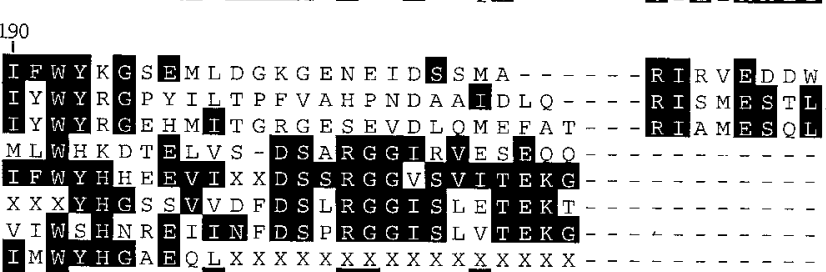

\section{政}

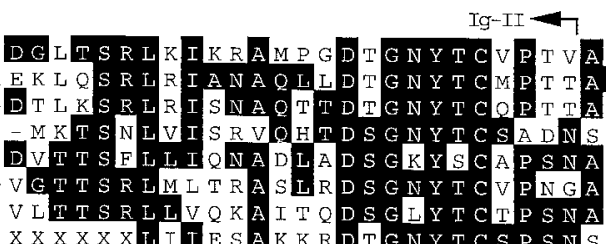

I MWYHGAEQLXXXXXXXXXXXXXXXX

\begin{tabular}{lll}
$X$ & $X X X X X X$ \\
\hline & $T S$
\end{tabular}

I N WFYNOKQIY L H R RGWR

ITWRHARLINYDTSRGGISVKTDM

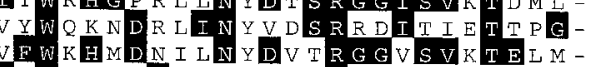

VFWRHMDILNYDVRRGVISVKTEL
TTWAKDEETLQGMTNRRLSVSDVW-

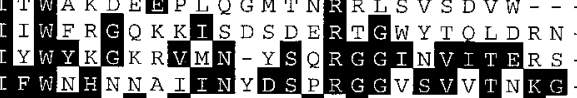

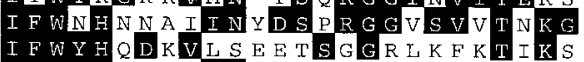

IFWYHDNRMINXXXXXXXXXXXXXX

R NIFG

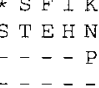

H N R NT T S I

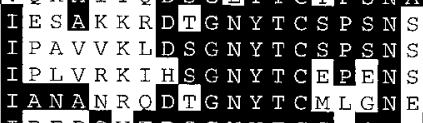

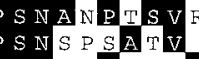
$P T S V R$
$S A T V$

\section{9}



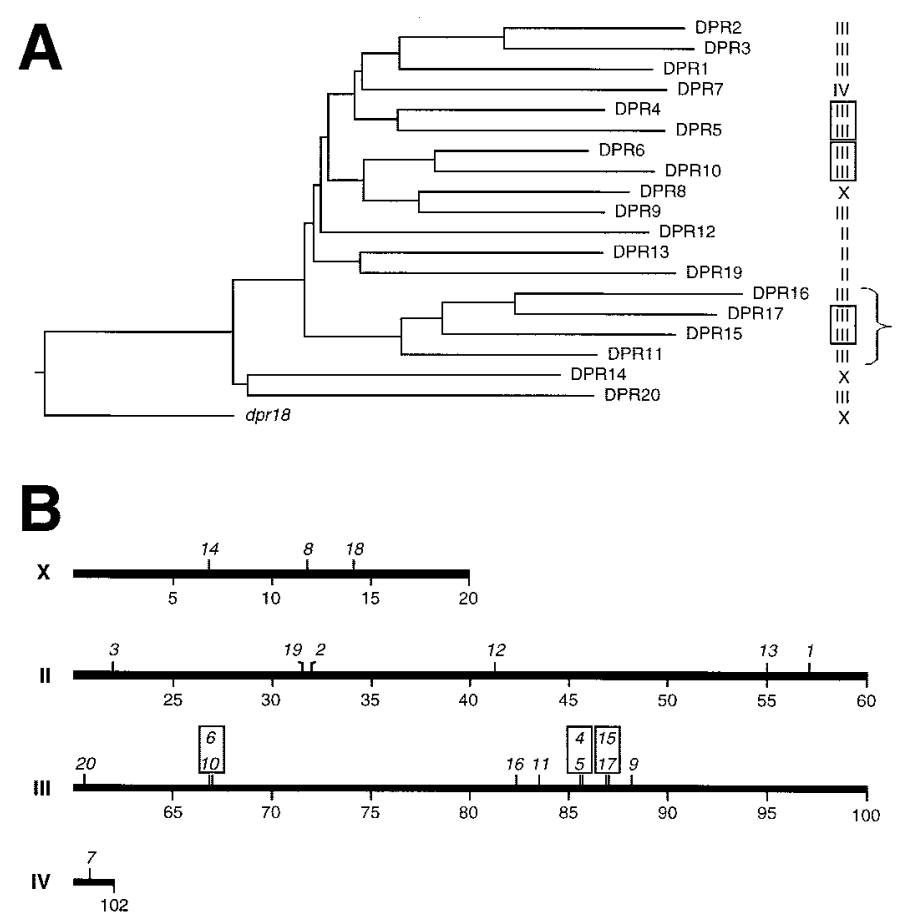

Figure 7. Correlation between relatedness of DIG proteins and chromosomal positions of corresponding genes. $A$, Dendrogram showing the relatedness of DIG proteins generated using MacVector 6.5.3 (Accelrys, Burlington, MA). The chromosome encoding each of the corresponding genes is shown to the right. The three pairs of tightly clustered genes are boxed. The bracket indicates a group of four $d p r$ genes clustered on chromosome III. B, Chromosomal map positions of $d p r$ genes. Those genes that are tightly clustered are boxed.

\section{DISCUSSION}

$d p r$, a locus required for the gustatory response to salt

One of the salient features of the $d p r$ mutation is that it specifically affects the salt aversion response and not the sugar response. Another mutation, Lot-94, which also affects salt aversion but not the sugar response, has been identified on the $\mathrm{X}$ chromosome; however, the locus has not been characterized at the molecular level (Falk and Atidia, 1975). Because the proportion of $d p r$ flies that extended their probosces in response to sucrose was similar to wild type, it appears that there was a defect in the salt suppression rather than a general effect on proboscis extension. $d p r$ was strongly expressed in the labelum and in two of the five neurons at the base of each taste bristle, consistent with electrophysiological observations that two sensory neurons are activated by salt stimulation (Fujishiro et al., 1984). Given the specific defect in the salt aversion response, those neurons that express $d p r$ are likely to be the salt-activated neurons. Thus, $d p r$ may provide a marker for the salt-responsive neurons in gustatory sensilla.

\section{DPR is an Ig domain protein functioning in sensory physiology}

Amino acid sequence analyses indicated that $d p r$ encoded a protein with two Ig repeats and a single transmembrane domain. Ig domains, which were originally identified among proteins involved in the immune response, are also present in a variety of proteins functioning in cell surface recognition in the nervous system (Williams and Barclay, 1988). Proteins containing Ig domains, many of which have been found in Drosophila, are classified into three groups: (1) transmembrane receptors, (2) secreted or membrane-bound ligands, and (3) cell adhesion molecules. Typical transmembrane receptors contain an enzymatic catalytic domain in the cytoplasmic region. Examples include the Drosophila FGF-receptor (breathless), which is linked to a tyrosine protein kinase domain (Klämbt et al., 1992; Shishido et al., 1993), and Ptp69D, which contains a tyrosine-specific phosphatase domain (Garrity et al., 1999).

DPR may not be a transmembrane receptor because the cytoplasmic domain is relatively short (75 amino acids) and is devoid of any known functional motif. Furthermore, the requirement for DPR in the salt-responsive neurons for suppression of the sugarinduced PER would not seem to be consistent with DPR functioning as a receptor, especially because salt stimuli interact directly with ion channels. Thus, it is plausible that DPR is a membrane bound cell adhesion molecule. An alternative function for DPR is that it may function as a ligand. Such a role has been demonstrated for a number of membrane-bound Ig-containing proteins (for review, see Yu and Kolodkin, 1999).

An important question concerns the mechanism through which the putative DPR ligand might lead to suppression of the sugar response. One possibility is that DPR is expressed in the saltresponsive neurons and associates with a receptor in axons of sugar-stimulated neurons. In response to high concentrations of salt, there may be suppression of synaptic activity in the circuit that is stimulated by the sugar receptors. It is less likely that DPR participates in cell fate determination because we did not observe any morphological abnormality in the nervous system in the $d p r$ adults. Furthermore, the same cells appeared to express the $d p r-G F P$ reporter in $d p r$ heterozygotes and homozygotes.

\section{DPR defines a subfamily of $\geq \mathbf{2 0}$ lg-containing proteins}

DPR is the founding member of a previously uncharacterized subfamily of Ig-containing proteins in Drosophila [DPR-Ig family (DIG)]. The DIG group may be larger than the 20 currently identified members because there are no DPR1 expressed sequence tags characterized by the BDGP, and conceptual translation of the Drosophila genomic sequences identified only a 31 amino acid fragment of DPR. DPR was nearly missed by the sequence analysis algorithm (GeneScan), possibly as a consequence of the relatively large introns and small exons that comprise the $d p r$ gene. Therefore, it is plausible that only small portions of other DPR-related proteins may be available. Consistent with this possibility, we found that DPR shares extensive homology to several additional Drosophila proteins that are predicted to be very short.

Finally, it will be of interest to ascertain whether any of the other DIG proteins participate in sensory physiology and whether they share partially redundant functions with DPR. Such a possibility may account for the observation that DPR is also expressed in the visual system; however, the visual response in $d p r$ flies was indistinguishable from that of wild type (our unpublished observations).

\section{REFERENCES}

Adams MD, Celniker SE, Holt RA, Evans CA, Gocayne JD, Amanatides PG, Scherer SE, Li PW, Hoskins RA, Galle RF, George RA, Lewis SE, Richard S, Ashburner M, Henderson SN, Sutton GG, Wortman JR, Yandell MD, Zhang Q, Chen LX, et al. (2000) The genome sequence of Drosophila melanogaster. Science 287:2185-2195.

Adler E, Hoon MA, Mueller KL, Chandrashekar J, Ryba NJ, Zuker CS (2000) A novel family of mammalian taste receptors. Cell 100:693-702.

Arora K, Rodrigues V, Joshi S, Shanbhag S, Siddiqi O (1987) A gene affecting the specificity of the chemosensory neurons of Drosophila. Nature 330:62-63.

Awasaki T, Kimura K (1997) pox-neuro is required for development of chemosensory bristles in Drosophila. J Neurobiol 32:707-721.

Benzer S (1967) Behavioral mutants of Drosophila isolated by countercurrent distribution. Proc Natl Acad Sci USA 58:1112-1119. 
Brand AH, Perrimon N (1993) Targeted gene expression as a means of altering cell fates and generating dominant phenotypes. Development 118:401-415.

Brümmendorf T, Rathjen FG (1993) Axonal glycoproteins with immunoglobulin- and fibronectin type II-related domains in vertebrates: structural features, binding activities, and signal transduction. J Neurochem 61:1207-1219.

Brümmendorf T, Rathjen FG (1995) Cell adhesion molecules 1: immunoglobulin superfamily. Protein Profile 2:963-1108.

Burg MG, Sarthy PV, Koliantz G, Pak WL (1993) Genetic and molecular identification of a Drosophila histidine decarboxylase gene required in photoreceptor transmitter synthesis. EMBO J 12:911-919.

Butler SJ, Ray S, Hiromi Y (1997) klingon, a novel member of the Drosophila immunoglobulin superfamily, is required for the development of the R7 photoreceptor neuron. Development 124:781-792.

Chandrashekar J, Mueller KL, Hoon MA, Adler E, Feng L, Guo W, Zuker CS, Ryba NJ (2000) T2Rs function as bitter taste receptors. Cell 100:703-711.

Chaudhari N, Landin AM, Roper SD (2000) A metabotropic glutamate receptor variant functions as a taste receptor. Nat Neurosci 3:113-119.

Clyne PJ, Warr CG, Carlson JR (2000) Candidate taste receptors in Drosophila. Science 287:1830-1834.

Deak II (1976) Demonstration of sensory neurones in the ectopic cuticle of spineless-aristapedia, a homeotic mutant of Drosophila. Nature 260:252-254.

Dethier VG, Solomon RL, Turner LH (1965) Sensory input and central excitation and inhibition in the blowfly. J Comp Physiol Psychol 60:303-313.

Dunipace L, Meister S, McNealy C, Amrein H (2001) Spatially restricted expression of candidate taste receptors in the Drosophila gustatory system. Curr Biol 11:822-835.

Falk R, Atidia J (1975) Mutation affecting taste perception in Drosophila melanogaster. Nature 254:325-326.

Falk R, Bleiser-Avivi N, Atidia J (1976) Labellar taste organs of Drosophila melanogaster. J Morphol 150:327-341.

Fujishiro N, Kijima H, Morita H (1984) Impulse frequency and action potential amplitude in labellar chemosensory neurons of Drosophila melanogaster. J Insect Physiol 30:317-325.

Garrity PA, Lee CH, Salecker I, Robertson HC, Desai CJ, Zinn K, Zipursky SL (1999) Retinal axon target selection in Drosophila is regulated by a receptor protein tyrosine phosphatase. Neuron 22:707-717.

Guan KL, Dixon JE (1991) Eukaryotic proteins expressed in Escherichia coli: an improved thrombin cleavage and purification procedure of fusion proteins with glutathione $S$-transferase. Anal Biochem 192:262-267.

Hartenstein V, Posakony JW (1989) Development of adult sensilla on the wing and notum of Drosophila melanogaster. Development 107:389-405

Hemperly JJ, Murray BA, Edelman GM, Cunningham BA (1986) Sequence of a cDNA clone encoding the polysialic acid-rich and cytoplasmic domains of the neural cell adhesion molecule N-CAM. Proc Natl Acad Sci USA 83:3037-3041.

Hiromi Y, Kuroiwa A, Gehring WJ (1985) Control elements of the Drosophila segmentation gene fushi tarazu. Cell 43:603-613.

Ishimoto H, Matsumoto A, Tanimura T (2000) Molecular identification of a taste receptor gene for trehalose in Drosophila. Science 289:116-119.

Karlstrom RO, Wilder LP, Bastiani MJ (1993) Lachesin: an immunoglobulin superfamily protein whose expression correlates with neurogenesis in grasshopper embryos. Development 118:509-522.

Karpen GH, Spradling AS (1992) Analysis of subtelomeric heterochromatin in Drosophila minochromosome Dp1187 by single P element insertion mutagenesis. Genetics 132:737-752.

Kinnamon SC, Margolskee RF (1996) Mechanisms of taste transduction. Curr Opin Neurobiol 6:506-513.

Klämbt C, Glazer L, Shilo B-Z (1992) breathless, a Drosophila FGF receptor homolog, is essential for migration of tracheal and specific midline glial cells. Genes Dev 6:1668-1678.

Kyte J, Doolittle RF (1982) A simple model for displaying the hydrophobic character of a protein. J Mol Biol 157:105-132.

Lindemann B (1996) Taste reception. Physiol Rev 76:718-766.

Maniatis T, Hardison RC, Lacy E, Lauer J, O'Connell C, Quon D, Sim GK, Efstratiadis A (1978) The isolation of structural genes from libraries of eucaryotic DNA. Cell 15:687-701.
Matsunami H, Montmayeur JP, Buck LB (2000) A family of candidate taste receptors in human and mouse. Nature 404:601-604.

Max M, Shanker YG, Huang L, Rong M, Liu Z, Campagne F, Weinstein H, Damak S, Margolskee RF (2001) Tas1r3, encoding a new candidate taste receptor, is allelic to the sweet responsiveness locus Sac. Nat Genet 28:58-63.

Montell C, Rubin GM (1988) The Drosophila ninaC locus encodes two photoreceptor cell specific proteins with domains homologous to protein kinases and the myosin heavy chain head. Cell 52:757-772.

Montmayeur JP, Liberles SD, Matsunami H, Buck LB (2001) A candidate taste receptor gene near a sweet taste locus. Nat Neurosci 4:492-498.

Moos M, Tacke R, Scherer H, Teplow D, Frueh K, Schachner M (1988) Neural adhesion molecule L1 as a member of the immunoglobulin superfamily with binding domains similar to fibronectin. Nature 334:701-703.

Nakamura M, Okano H, Blendy JA, Montell C (1994) Musashi, a neural RNA-binding protein required for Drosophila adult external sensory organ development. Neuron 13:76-83.

Nelson G, Hoon MA, Chandrashekar J, Zhang Y, Ryba NJ, Zuker CS (2001) Mammalian sweet taste receptors. Cell 106:381-390.

Nielsen H, Engelbrecht J, Brunak S, von Heijne G (1997) Identification of prokaryotic and eukaryotic signal peptides and prediction of their cleavage sites. Protein Eng 10:1-6.

Palka J, Lawrence PA, Hart HS (1979) Neural projection patterns from homeotic tissue of Drosophila studied in bithorax mutants and mosaics. Dev Biol 69:549-575.

Pimenta AF, Zhukareva V, Barbe MF, Reinoso BS, Grimley C, Henzel W, Fischer I, Levitt P (1995) The limbic system-associated membrane protein is an Ig superfamily member that mediates selective neuronal growth and axon targeting. Neuron 15:287-297.

Pirrotta V (1986) Cloning Drosophila genes. In: Drosophila, a practical approach (Roberts DR, ed), pp 83-110. Washington, DC: IRL.

Pollard TD (1984) Purification of a high molecular weight actin filament gelation protein from Acanthamoeba that shares antigenic determinants with vertebrate spectrins. J Cell Biol 99:1970-1980.

Robinow S, White K (1991) Characterization and spatial distribution of the ELAV protein during Drosophila melanogaster development. J Neurobiol 22:443-461.

Rubin GM, Spradling AC (1982) Genetic transformation of Drosophila with transposable element vectors. Science 218:348-353.

Sainz E, Korley JN, Battey JF, Sullivan SL (2001) Identification of a novel member of the T1R family of putative taste receptors. J Neurochem 77:896-903.

Scott K, Brady Jr R, Cravchik A, Morozov P, Rzhetsky A, Zuker C, Axel R (2001) A chemosensory gene family encoding candidate gustatory and olfactory receptors in Drosophila. Cell 104:661-673.

Sepp KJ, Auld VJ (1999) Conversion of lacZ enhancer trap lines to GAL4 lines using targeted transposition in Drosophila melanogaster. Genetics 151:1093-1101.

Shanbhag SR, Park SK, Pikielny CW, Steinbrecht RA (2001) Gustatory organs of Drosophila melanogaster: fine structure and expression of the putative odorant-binding protein PBPRP2. Cell Tissue Res 304:423-437.

Shiraishi A, Tanabe Y (1974) The proboscis extension response and tarsal and labellar chemosensory hairs in the blowfly. J Comp Physiol 92:161-179.

Shishido E, Higashijima S, Emori Y, Saigo K (1993) Two FGF-receptor homologues of Drosophila: one is expressed in mesodermal primordium in early embryos. Development 117:751-761.

Singh RN (1997) Neurobiology of the gustatory systems of Drosophila and some terrestrial insects. Microsc Res Tech 39:547-563.

Spradling AC, Rubin GM (1982) Transposition of cloned P elements into Drosophila germline chromosomes. Science 218:341-347.

Stocker RF (1994) The organization of the chemosensory system in Drosophila melanogaster: a review. Cell Tissue Res 275:3-26.

Ueno K, Ohta M, Morita H, Mikuni Y, Nakajima S, Yamamoto K, Isono K (2001) Trehalose sensitivity in Drosophila correlates with mutations in and expression of the gustatory receptor gene Gr5a. Curr Biol 11:1451-1455.

Williams AF, Barclay AN (1988) The immunoglobulin superfamilydomains for cell surface recognition. Annu Rev Immunol 6:381-405.

Winberg ML, Perez SE, Steller H (1992) Generation and early differentiation of glial cells in the first optic ganglion of Drosophila melanogaster. Development 115:903-911.

Yu HH, Kolodkin AL (1999) Semaphorin signaling: a little less perplexin. Neuron 22:11-14. 